\title{
Provider perspectives on informed consent in female sterilisation services: Findings from a facility-based study in Chennai
}

Raja Lakshmi

Follow this and additional works at: https://knowledgecommons.popcouncil.org/departments_sbsr-rh

Part of the Demography, Population, and Ecology Commons, Family, Life Course, and Society Commons, International Public Health Commons, and the Women's Health Commons How does access to this work benefit you? Let us know!

\section{Recommended Citation}

Rajalakshmi. 2007. "Provider perspectives on informed consent in female sterilisation services: Findings from a facility-based study in Chennai," Health and Population Innovation Fellowship Programme Working Paper no. 3. New Delhi: Population Council. 

This report is the result of a project entitled "Informed Consent in Reproductive Health Services," undertaken as part of the Health and Population Innovation Fellowship (HPIF) awarded to the author in 2004.

The HPIF programme is administered by the Population Council, New Delhi and is a continuation of the MacArthur Foundation's Fund for Leadership Development (FLD) fellowship programme that continued over the period 1995 to 2004. The Council is grateful to the MacArthur Foundation for its support to this programme.

The HPIF programme aims to support mid-career individuals who have innovative ideas, leadership potential, and the capacity to help shape policy and public debate in the field of population, reproductive health and rights in general, with a focus on two priority themes - maternal mortality and morbidity, and the sexual and reproductive health and rights of young people. Since the transfer of the programme to the Population Council through 2006, a total of 17 individuals have been supported under the HPIF programme.

\section{For additional copies of this report, please contact:}

Rajalakshmi

Kuber Bhawan

1, Puliyur First Main Road

Trustpuram, Kodambakkam

Chennai - 600024

Phone: 044-24816767

Email: rajalaksh@gmail.com
Population Council

Zone 5A, Ground Floor

India Habitat Centre, Lodi Road

New Delhi - 110003

Phone: 011-2464 2901/02

Email:info-india@popcouncil.org

Web site: http://www.popcouncil.org/asia/india.html

The Population Council is an international, non-profit, non-governmental organisation that seeks to improve the well-being and reproductive health of current and future generations around the world and to help achieve a humane, equitable and sustainable balance between people and resources. The Council conducts biomedical, social science and public health research, and helps build research capacities in developing countries.

\section{Copyright @ 2007 Rajalakshmi}

About the author: Rajalakshmi has a Master of Arts in Social Work from the Tata Institute of Social Sciences, Mumbai and a B.A. in Psychology from the University of Madras. She holds a Diploma in Medical Law and Ethics (NLSIU) and is trained in International Health Research Ethics at the Harvard School of Public Health. She has worked in the area of reproductive health and women's rights since 1998. Her last assignment was with the Centre for Women and Law, National Law School of India, Bangalore, as a Research Associate.

Suggested citation: Rajalakshmi. 2007. "Provider Perspectives on Informed Consent in Female Sterilisation Services: Findings from a Facility-based Study in Chennai, "Health and Population Innovation Fellowship Programme Working Paper, No. 3. New Delhi: Population Council.

\section{(P) Population Council}




\section{Provider Perspectives on Informed Consent in Female Sterilisation Services}

FINDINGS FROM A

FACILITY-BASED STUDY IN CHENNAI

Rajalakshmi

Fellow

Health and Population Innovation Fellowship Programme 



\section{Contents}

Introduction

Informed consent

What is informed consent?

What do we know about the consent taking process in India?

A description of the study

Study setting

Methodology

Profile of the study participants

Providers' reports of the consent taking process

Quality of information provided: How comprehensive?

Providing information on alternatives to sterilisation

Providing information on the risks of sterilisation

Providing information on the possible failure of sterilisation

Quality of decision-making: How voluntary?

Providers' attitudes to information giving 12

Providers' attitudes to client involvement 13

Compulsion in client-provider interaction 15 
Quality of written consent taking: How informed and free?

Purpose of the consent form

Administration of the consent form

Need for consent from husband

or other family members

Providers' perceptions of the importance of informed consent

Informed consent as an information providing process

Informed consent as a means of preparing for surgery

Informed consent as a signature on a form

Informed consent as a medico-legal requirement

Informed consent as a two-way communication process

and a client's right

Conclusion and recommendations

References

Acknowledgements

\section{List of tables}

Table 1: Profile of the study sample 


\section{Introduction}

The ethical bases for informed consent in health care services lie in the principles of autonomy, self-determination and truth telling (Cook, Dickens and Fathalla, 2003). The Declaration of Helsinki notes that "after ensuring that the subject has understood the information, the physician should then obtain the subject's freely given informed consent" (WMA, 2000). Informed consent in the provision of any method-specific family planning service involves formal authorisation by the client, based on adequate information provided, which is given of her/his own free will. The duty of providers is to present information in a form that the client can assimilate and recall in order to make or review a decision (Cook, Dickens and Fathalla, 2003). Providing consent to accept a particular service however, goes far beyond signing a consent form. For consent to be informed, three key elements are necessary: information provided by the provider to the client should be comprehensive and understood by the client; the consent taking process should be transparent; and interaction between the provider and the client such that the client feels secure to exercise her/his will.

In India, few studies have explored the exercise of informed consent as an intrinsic part of quality of care, as a client's right or as part of the ethics of service delivery. Even fewer studies have been undertaken on these issues from the perspective of providers. The objective of this paper is to explore the perceptions and experiences of providers with regard to the process of informed consent in the provision of female sterilisation services in Chennai, south India. It describes the quality of information provided to clients of sterilisation, providers' attitudes to clients and the quality of decision-making, as well as the quality of the consent taking process in this setting. In addition, providers' perceptions of the importance of informed consent are discussed. Findings are intended to enhance awareness of issues related to informed consent among providers and to demonstrate the need to strengthen the role of providers in ensuring women's right to informed consent. 


\section{Informed consent}

\section{What is informed consent?}

Access to information is a client's right and correspondingly, it is the ethical duty of providers to give clients relevant information. The critical information that providers should share with clients is with regard to the choice of contraceptive methods available, how each method works and its relative advantages and disadvantages. With regard to sterilisation, for example, providers need to inform their clients that it is an irreversible method and there are chances of regret in the future; moreover, clients need to be given details of the surgical procedure involved (Baill, Cullins and Pati, 2003).

Informed consent also implies the need to protect the client's right to consent out of her or his own free will. The quality of interaction between the provider(s) and the client clearly influences both the extent to which the client feels comfortable discussing her concerns with regard to methods or procedures and the extent to which she can actually provide consent out of her own free will. Indeed, the process of informed consent creates an optimal relationship between the provider(s) and the client where the client's interests are protected (Kennedy, 1991).

Providers need to engage with their clients to gauge their needs, and tailor information accordingly (Cook, Dickens and Fathalla, 2003; Kim, Kols and Mucheke, 1998). While providers may recommend certain family planning method to clients, they must refrain from being directive, compelling or unduly induce a decision that may not be appropriate to the client's reproductive health status, needs and goals (Cook, Dickens and Fathalla, 2003). The provider's responsibility is to convey accurate information that the client can understand, and allow adequate time to make patient deliberation possible (Baill, Cullins and Pati, 2003). In addition to guarding against influencing the client's decision, the provider is also obliged to ensure that the woman is not being coerced to adopt the procedure by family members or others. Indeed, truly free and voluntary consent depends largely on these affective components of client-provider interaction, identified by Bruce as interpersonal relations (Bruce, 1990). Providers' attitudes to women in general, their biases against specific groups and their personal opinion on rights and ethics all have a bearing not only on the nature of communication with their clients but also affect the quality of information and the decision-making process. Hence the quality of provider-client interaction becomes an important component of the consent process.

Informed consent in the context of family planning is not a one-time event; it starts with the first encounter between a provider and a potential client of sterilisation such as during an antenatal check-up, contraceptive counselling or when a client accesses abortion services. The information provided can be new, or a clarification of a doubt, or advice, which would help the client in arriving at a decision. While the client may continue to seek information/ advice from other sources, the provider remains the main source of information. 
In countries like India, family planning is promoted by the government through several channels, such as audio-visuals, the print media and direct contact, which implies that the information provided should be fairly standardised so that there is consistency across different sources. The client then arrives at a final decision and signs a document, especially in cases where surgery is involved. The taking of a consent signature on a written, dated form does not however, constitute the whole informed consent process; it is only an authorisation given by the client for a prescribed method. In fact there could be withdrawal of consent even after a signature is obtained where the provider continues to inform the client (termed “informed dissent”; see Cook, Dickens and Fathalla, 2003).

There are several international and national guidelines on procedures to ensure informed consent for family planning services. Both the Helsinki Declaration and the Report of the National Bioethics Advisory Commission in the US highlight a shift in emphasis from "informed" to "understood" consent (National Bioethics Advisory Commission, 2001; WMA, 2000). Guidelines issued by the International Planned Parenthood Federation (IPPF) on female sterilisation stress that counselling should precede consent taking; forms should be signed by the person undergoing the surgery and by the surgeon; the content form should be read out to non-literate persons and explained in terms that clients can understand; and forms should be available in the local language (IPPF website). Guidelines for female and male sterilisation prepared by the Ministry of Health and Family Welfare (MOHFW), Government of India require giving clients information on all available contraceptive methods, their side effects and complications; use of simple language; and ensuring that the client is not under sedation or physical/mental stress while consent is taken; moreover, the consent form should list the rights of clients and the duties of providers, including the need to ensure voluntary choice (MOHFW, 1999).

The MOHFW guidelines clearly state that the signature of the partner is not required for sterilisation. Recently, however, in March 2007, the Supreme Court passed a judgement that challenges this procedure and stresses the need to obtain spousal consent for sterilisation. According to the judgement, when a husband or wife submits himself/herself to sterilisation without the knowledge of the other without any valid medical reason, it may amount to mental cruelty and can be considered as a valid ground for divorce (Supreme Court of India website, Ghosh vs. Ghosh, Appeal [Civil] 151 of 2004). This judgement has however, no bearing on the consent taking process, which continues to require only the consent of the person undergoing the procedure.

\section{What do we know about the consent taking process in India?}

While the MOHFW has made available guidelines on the consent taking process, these guidelines have been poorly implemented in India. In March 2005 the Supreme Court, in response to a public interest litigation in Ramakant Rai vs. Union of India, observed that there was no uniformity in the standards and procedures being followed in conducting sterilisations across states, and laid down the following directions: that state governments should set up a panel of approved doctors, who have at least five years experience in gynaecology, to conduct sterilisations; that the states should maintain a checklist with details of the client's age, health status and number of children, to be filled up by the doctor 
performing the procedure; that a uniform proforma should be used to obtain consent from the client before performing the surgery; and that details of persons undergoing sterilisation and the number of deaths that occur during or after sterilisation should be registered. It also empowered state governments to hold inquiries into any breach of the guidelines and to take punitive action against doctors and organisations that were not adhering to the guidelines. The Supreme Court expressed concern over deaths caused by unregulated sterilisations in the country; it ordered that a compensation of Rs. 1 lakh be paid to the next of kin in case of death following sterilisation and Rs. 30,000 in case of incapacity or post-operative complications, to be effective till a uniform insurance policy was introduced (Supreme Court of India website, Ramakant Rai. Vs. Union of India, W.P No. 209/2003). In fact, by the end of 2005, the MOHFW had brought out an insurance scheme for failure, death and medical complications arising out of sterilisation and an indemnity cover for the doctor/health facility performing the sterilisation procedure (MOHFW, 2005). In addition, the MOHFW has provided for the setting up of a Quality Assurance Committee (QAC) at the state and district levels to monitor and evaluate that the family planning services are being provided in accordance with the guidelines issued by Government of India (MOHFW, 2005).

As noted, little is known about the consent taking process in India; what is known comes from studies of quality of care in reproductive health. One of the fundamental elements identified in the framework for assessing quality of care in family planning services is the provision of information to clients (Bruce, 1990). Few studies have however, explored the role of the provider in the process of taking informed consent.

According to available evidence, only a small proportion of providers give clients information on family planning methods other than sterilisation or inform them of the side effects of various contraceptive methods. For example, in a study in rural Uttar Pradesh in 1993-94, only 33-42 percent of ever-married women reported that providers had discussed any method of family planning other than sterilisation; 33 percent were told about vasectomy, 35 percent about intra-uterine devices (IUDs), 36 percent about condoms and 42 percent about pills (Khan, Gupta and Patel, 1999). In a multi-centric study of currently married women in the reproductive age group in four states in India, only 43 percent of women in Karnataka reported they were informed about spacing methods in addition to sterilisation, followed by 26 percent both in Tamil Nadu and West Bengal respectively; in Bihar only 18 percent reported that they were similarly informed (Roy and Verma, 1999). According to the National Family Health Survey-2 (NFHS-2), while nationally, 19 percent of currently married women who were current users of modern family planning methods were informed about other methods of family planning by a public sector provider and 28 percent by a provider in a private facility, in Tamil Nadu 7 percent and 22 percent of women respectively were similarly informed (IIPS and ORC Macro, 2000). A recent follow-up study in Tamil Nadu (2002-03) shows that 23 percent of currently married sterilised women or their husbands were informed of alternative contraceptive methods at the time of sterilisation (IIPS and Johns Hopkins, 2005). 
Studies also show that the proportion of women reporting that they were informed about the side effects of various family planning methods was low. Only 22 percent of evermarried women in rural Uttar Pradesh were informed about both the advantages and disadvantages of sterilisation (Khan, Gupta and Patel, 1999). In the multi-centric study referred to above, 47 percent of currently married women in the reproductive age group in Tamil Nadu were informed about the side effects of contraceptives, compared to 40 percent in West Bengal, 58 percent in Bihar and 89 percent in Karnataka (Roy and Verma, 1999). According to NHFS-2, among currently married women using modern contraceptive methods, 55 percent of women in Tamil Nadu were informed of the side effects of sterilisation by a health or family planning worker at the time of accepting sterilisation (compared to $22 \%$ nationally) (IIPS and ORC Macro, 2000). In the follow-up study, the proportion of currently married sterilised women or their husbands who were told about the side effects of sterilisation was 69 percent in Tamil Nadu (IIPS and Johns Hopkins, 2005). A study of four Indian states, including Tamil Nadu, reports that providers focused on female sterilisation and IUDs rather than discussing all available contraceptive methods, chose the method for the client rather than letting the client choose and were under pressure to recruit acceptors (Verma and Roy, 1999).

A few studies have discussed as to why providers do not give clients comprehensive information. Providers feel, for example, that they are not required to discuss alternative methods and their side effects once a client has "voluntarily" chosen sterilisation (Visaria, 2000). Indeed, studies in rural Maharashtra and Kerala show that providers perceived that giving information on the side effects of methods such as sterilisation would discourage women from accepting the method (Kumar, 2001; Murthy, 1999). Pressure to achieve family planning targets has also been noted as a possible reason for giving clients incomplete/ selective information (Khan, Gupta and Patel, 1999; Verma and Roy, 1999).

Studies have rarely explored the elements that influence the process of contraceptive decisionmaking; however, several studies have focused on the quality of client-provider interaction in India, including frequency of visits, time spent, attention, cordiality and privacy. These studies have reported poor quality of client-provider interaction, including improper treatment, lack of respect for poor women and inadequate attention in general (Murthy, 1999; Roy and Verma, 1999; Van Hollen, 2003). A study in rural Maharashtra reports provider bias against poor women, where certain information was more likely to be given to better-off women than to poor women (Murthy, 1999). Other studies report that abortion services are made available to clients contingent on their acceptance of sterilisation or IUD, particularly in the public sector, resulting in many women turning to the private sector for services (Ravindran, 1999; Van Hollen, 2003). Providers' insistence on obtaining the spouse's signature has also been documented in abortion services (Gupte, Bandewar and Pisal, 1999; Ravindran, 1999). 


\section{A description of the study}

\section{Study setting}

Data are drawn from a study conducted in Chennai, the capital of Tamil Nadu state. Tamil Nadu is one of the more socio-economically developed states in India, characterised by higher levels of female literacy compared to other states (64.4\% compared to the all-India average of $53.7 \%$; Tamil Nadu Government website). Fertility and maternal mortality rates, likewise, are considerably below the national average; for example, in 2001 the mean number of children per woman in Tamil Nadu was 2.9 compared to the all-India average of 3.8 (RGI, 2005); similarly, the maternal mortality rate for Tamil Nadu was 8.8 in 2001 03 as compared to the all-India average of 27.4 (RGI, 2006).

Tamil Nadu is also one of the states where awareness of family planning and use of contraception is high. As of 1998-99, knowledge of at least one modern contraceptive method was universal in Tamil Nadu; 52.1 percent of currently married women were using some method of contraception (compared to the national average of $48 \%$ ), of whom 88 percent had adopted female sterilisation (IIPS and ORC Macro, 2000). Female sterilisations have increased in the state from 370,000 conducted in 1999-2000 to 430,000 in 2003-04 (Tamil Nadu Government, Directorate of Family Welfare website). Age of women and parity at sterilisation are low: 60 percent of sterilisation acceptors had two or fewer children in 1998-99 (Tamil Nadu Government, Directorate of Family Welfare website); the median age at acceptance was 25 years in 1998-99 (IIPS and ORC Macro, 2000).

Chennai is well-known for its medical services. It has 110 corporation (public) health centres, four teaching centres with attached tertiary care centres (Sreevidya and Sathiyasekaran, 2003) and approximately 400 private hospitals for a total population (including the suburbs) of nearly 8 million. The ratio of beds in private/public facilities in the city is about 48:52. Government doctors work as consultants in private hospitals or run their own clinics/ hospitals (Muraleedharan, 1999).

\section{Methodology}

This report is based on the findings of a study in Chennai that explored experiences with and perceptions of informed consent among both clients and providers of family planning services. Data were gathered between December 2004 and December 2005. The study involved both a survey and in-depth interviews conducted in a total of 18 hospitals (two public-cum-teaching hospitals and 16 private hospitals/nursing homes, of which one was a teaching hospital) in Chennai that provide family planning and/or abortion services. The profile of the hospitals varied considerably: for example, the smallest was a 10-bedded facility, and the largest had 1,500 beds. Some were multi-specialty facilities while others were dedicated to gynaecology and obstetrics. Of these, two large private hospitals did not offer medical termination of pregnancy (MTP) services as a policy. 
Data on the perspectives of providers, analysed in this report, are entirely qualitative and include 38 in-depth interviews with providers from the 18 hospitals. Only those providers who performed sterilisations, or provided abortion or IUD services, were interviewed. Para-professionals were also interviewed if they provided information to clients about these services and if they were responsible for taking written consent. The client component, which is not covered in this report, comprised exit interviews with a total of 712 women at these facilities. In-depth interviews were conducted with 18 clients. Five focus group discussions with clients and non-clients in poor neighbourhoods and 13 key informant interviews were also conducted.

Providers were informed about the purpose of the study and ensured anonymity. Permission was sought to tape-record the discussion, which was however, refused by most providers in public hospitals. Interviews lasted on an average for one hour. Followup interviews were conducted with a few providers in order to clarify doubts or to gather additional information.

\section{Profile of the study participants}

In all, interviews were conducted with 21 doctors; seven nurses; five para-professionals including auxiliary nurse-midwives (ANMs), Health Visitors, counsellors and social workers; and five post-graduate students. Table 1 presents a profile of the providers in the study setting.

All the respondents but one were female. Post-graduate students were on an average 10 years younger than the doctors (27.4 and 37.0 years respectively); nurses and paraprofessionals were of approximately the same age (33.6 years and 30.8 years respectively). As expected, compared to doctors, nurses and para-professionals, the mean years of experience of post-graduate students was the lowest (3.6 years compared to 11.4, 11.7 and 13.2 years respectively).

Of the 21 doctors, 17 had a post-graduate degree or diploma (MD, DNB, DGO, MRCS, FACOG). ${ }^{1}$ With the exception of one doctor who worked in a public facility, the majority worked either exclusively in a private facility or in both public and private facilities. Of those working only in a private facility, two owned medium-sized hospitals while the rest were consultants in medium or large hospitals. Three doctors headed their departments and 10 were also involved in teaching. Four doctors in the private sector had specialised training from foreign universities. The majority of private doctors were also trained in laparoscopy.

1 MD: Doctor of Medicine; DNB: Diplomate of National Board; DGO: Diploma in Gynaecology \& Obstetrics;
MRCS: Member of Royal College of Surgeons; FACOG: Fellow of the American College of Obstetrics and Gynaecology. 7 Provider Perspectives on Informed Consent in Female Sterilisation Services 
Five of the seven nurses interviewed worked in private facilities. Two of the five paraprofessionals worked in government hospitals; the rest worked either exclusively in a private facility or at both private and government facilities. Para-professionals were responsible for motivating women, giving information to clients and administering the consent form. The five post-graduates were either studying for an MD or a Diploma in Gynaecology and Obstetrics.

Table 1:

Profile of the study sample

\begin{tabular}{|c|c|c|c|c|c|}
\hline & Doctors & Nurses & $\begin{array}{l}\text { Para- } \\
\text { professionals }\end{array}$ & $\begin{array}{l}\text { Post-graduate } \\
\text { students }\end{array}$ & Total \\
\hline Total $(\mathbf{N})$ & 21 & 7 & 5 & 5 & 38 \\
\hline $\begin{array}{l}\text { Female } \\
\text { Male }\end{array}$ & $\begin{array}{c}20 \\
1\end{array}$ & $\begin{array}{l}7 \\
0\end{array}$ & $\begin{array}{l}5 \\
0\end{array}$ & $\begin{array}{l}5 \\
0\end{array}$ & $\begin{array}{c}37 \\
1\end{array}$ \\
\hline Mean age & $37.4 *$ & 33.6 & 30.8 & 27.4 & 34.3 \\
\hline $\begin{array}{l}\text { Mean years of } \\
\text { experience }\end{array}$ & 11.4 & 11.7 & 13.2 & 3.6 & 12.5 \\
\hline $\begin{array}{l}\text { Facility where } p \\
\text { works }\end{array}$ & & & & & \\
\hline $\begin{array}{l}\text { Public facility } \\
\text { Private facility } \\
\text { Both }\end{array}$ & $\begin{array}{c}1 \\
11 \\
9\end{array}$ & $\begin{array}{l}2 \\
5 \\
-\end{array}$ & $\begin{array}{l}2 \\
2 \\
1\end{array}$ & $\begin{array}{l}2 \\
1 \\
2\end{array}$ & $\begin{array}{c}7 \\
19 \\
12\end{array}$ \\
\hline
\end{tabular}

*Based on 20 responses as one doctor refused to disclose her age. 


\section{Providers' reports of the consent taking process}

\section{Quality of information provided: How comprehensive?}

As noted earlier, a key component of informed consent is the provision of comprehensive information to the client. However, providers rarely informed clients about alternative methods of family planning, discussed the sterilisation procedure, or gave them details about possible side effects and the risk of failure. Findings show that the content and timing of information given to clients varied across providers.

\section{Providing information on alternatives to sterilisation}

Interviews confirm that although providers (doctors and post-graduate students) agreed that a cafeteria approach was appropriate, many did not discuss the various contraceptive methods with their clients and instead counselled them to undergo sterilisation, especially if the woman was multi-parous. Other methods of contraception were generally only discussed with women who were diagnosed with serious contraindications, such as heart disease; these clients were advised to accept non-terminal female methods including IUDs, oral contraceptives or injectables. Vasectomy was rarely included as an option; indeed only three providers, all of whom were from the private sector, said that they discussed vasectomy routinely while discussing tubectomy.

\section{Providing information on the risks of sterilisation}

Providers reported a range of reasons for promoting female sterilisation. For example, as the following quotes indicate, providers argued that the method was simple, safe and effective, with minimal side effects or complications, and rarely resulted in failure. Therefore, discussing the rare possibility of risk/failure with clients was considered unnecessary. ${ }^{2}$

There are no side effects of sterilisation. There is only a very small chance of failure.

(Dr. SP, post-graduate student, 29 years, 7 years experience, private facility)
I: Other than failure, no risks?
R: No, no, no, no, no.
I: Or complications?
$\mathrm{R}$ : No, no... absolutely not.

\footnotetext{
2 Although a low-risk procedure, female sterilisation has a complication rate of 1\% (Rotimi and Eedarapalli website) and a failure rate of 1-2\% (MOHFW, 1999). Applying these rates to the total of 55,052 female sterilisations conducted in Chennai in 2004-05 (Tamil Nadu Government, Directorate of Family Welfare website), there would have been around 825 cases of failure and 550 cases of complications in that year alone.
}

9 Provider Perspectives on Informed Consent in Female Sterilisation Services 

I: Or side effects?
R: No...absolutely not.
I: You tell them [clients] there are no side effects?
$\mathrm{R}$ : Yes, then they agree [to undergo sterilisation]. (Dr. RJ, 36 years, 13 years experience, private facility)

The only risks that some providers mentioned were those related to the administration of anaesthesia, which are risks associated with any type of surgery. Providers acknowledged the side effects and risks of sterilisation only when investigators asked them to compare female sterilisation with male sterilisation or different laparoscopy methods.

Clients were seldom informed about the possible complications of sterilisation. Nurses, ANMs and doctors generally avoided such discussions as they perceived that they would frighten women.
I: Do you tell clients about complications of sterilisation?
$\mathrm{R}$ : We should inform them... [but] we do not tell them about complications. We tell them only the good things [about sterilisation]. Mostly we do not tell them [about complications]. (Para-professional RV, 33 years, 12 years experience, public facility)

We don't talk about complications such as bladder injury or bowel injury, which very rarely occur. There is no point scaring them [clients], but we mention it in the consent form for them to read. (Dr. RG, 48 years, 24 years experience, private facility)

\section{Providing information on the possible failure of sterilisation}

Similarly, the possibility of sterilisation failure was rarely discussed with prospective clients. Just as providers' views on the risks of different methods of sterilisation varied, they also seemed uncertain about failure rates, which they cited as ranging from 0.1-10.0 percent (Government of India estimates failure rates at 1-2\% [MOHFW, 1999]). In interactions with clients, providers tended to focus only on the positive aspects of sterilisation, arguing that negative information would inhibit clients from accepting the method and should be provided only following sterilisation, if at all.

[We don't tell them about the possibility of failure] Not on a routine basis. If we tell them, women will ask more and more questions about it... when they need the answers, we tell them, otherwise we don't tell because I don't think the patient should be informed. (Dr. T, 43 years, 12 years experience, private facility)

We cannot discourage them about this [failure of sterilisation]....If we say all this [discuss failure], no one will ever want to undergo sterilisation....Our purpose [of promoting small families] will not be solved....For all other surgeries, except sterilisation, we talk about failure rates because even a 1 percent failure would discourage women. They will say, "Then there is no need". (Dr. NP, 43 years, 18 years experience, private facility) 
Some providers reported that they did not raise the issue of failure as it would reflect poorly on the skills of the doctor and affect the client's confidence in the provider. Some even believed that women were aware that there was a possible chance of failure of sterilisation.

Providers generally gave clients information on the possibility of sterilisation failure only at the time of post-sterilisation care. At the time of discharge women were merely instructed to avoid intercourse for some time and to return if they missed their periods; they were not told why they should do so or the consequences of not reporting a missed period. A few providers reported that they explained the likely failure of the procedure to women only during follow-up visits:

We don't tell [the client about the possibility of failure], not to all the cases, as they will think that the doctor is inefficient or did not do the operation properly. We ask them to come back if they don't get their periods. In my experience there has been one failure so far. (Dr. L, 62 years, 30 years experience in public facility and last 5 years in private facility)

After completing the sterilisation...after sending them [patients] home, discharge and all that... after one month, during review, we discuss failure and counsel them [patients]. (Dr. NP, 43 years, 18 years experience, private facility)

Narratives suggest that even in cases where women had experienced failure, information provided tended to be superficial and providers did not feel accountable to explain why the procedure had failed. Reasons for failure were rarely provided.

I: If there is a failure in sterilisation, how do you deal with it?

$\mathrm{R}$ : Tell them that because you have more tissue, one tube has joined. That is why this has happened to you. We talk to them nicely and tell them that we will do re-sterilisation and send them back. (Dr. SL, 40 years, 14 years experience, public facility)

A few providers however, did perceive that it was important to inform women in advance about the possibility of failure or complications so that it would not cause them unnecessary stress. They reasoned that women themselves would become more vigilant and report a possible post-sterilisation pregnancy early. These providers noted that they conveyed information to women in a positive way to encourage them to accept the method, stressing, for example, that the success rate of sterilisation was 99 percent rather than that the failure rate was 1 percent.

... it is how you put it. I say there is no guarantee in the procedure. I start like this — what is the guarantee that when you are walking on the street, you will not get hit by a car? [That is] much more than the failure rate for sterilisation. It is very, very remote [failure] but it can happen; it is not 100 per cent foolproof. (Dr. BK, 35 years, 5 years experience, private facility)

Providers in private hospitals were more likely to provide this information to their clients largely to protect themselves in case of failure. For example:

11 Provider Perspectives on Informed Consent in Female Sterilisation Services 
I: Do you inform the patients regarding chances of failure?

R: In private facilities we take all precautions. (Dr. WT, 54 years, 28 years experience, public facility)

In short, providers' narratives underscore that they tended to project female sterilisation as a method free of risk, complications and side effects. There was slight willingness to acknowledge the negative aspects of the method only when probed. This implies that an average client is unlikely to have access to complete and unbiased information on sterilisation. While one reason why providers do not give information on possible complications is to increase acceptance, the fact that even a basic explanation of the sterilisation procedure is not provided is indicative of providers' lack of sensitivity of the clients' right to comprehensive information.

\title{
Quality of decision-making: How voluntary?
}

Both the IPPF and MOHFW guidelines underscore the need for providers to provide a space and encourage the client to ask questions and address her concerns before she gives informed consent. It is the ethical responsibility of the provider to ensure that the decision arrived at by the client is voluntary, informed and based on adequate understanding, and not taken under pressure. Provider attitudes to clients and the involvement of clients in the decision-making process determine the quality of information they receive and the extent to which they are pressured to accept sterilisation by providers.

\section{Providers' attitudes to information giving}

The study revealed that providers' patronising and judgemental attitude towards clients affected the quality and content of information they gave to women. Some providers were of the view that clients from poor families, who were illiterate or who sought care from a public hospital, were incapable of demanding and understanding information; these clients were reluctant to ask questions and relied on providers to make the appropriate contraceptive decision for them. For example:

\begin{abstract}
Most of them [patients who can afford to pay] know everything, but to those on the other side [non-paying patients], even if we explain, they won't understand because their understanding capacity is low. (Dr. SP, post-graduate student, 29 years, 7 years experience, private facility)
\end{abstract}

Moreover, information was likely to be withheld from poor or poorly educated clients because providers believed that without some basic education or awareness, women would not be able to absorb information, voice concerns or seek clarifications. Similarly, clients of public sector services were given less detailed information than those who used private sector facilities. For example:

Giving information is important. But in the government set-up it is very difficult because there is no time, plus educated people don't come there. So whatever we tell them [the clients] they won't understand at all. They don't have basic knowledge to understand the information that we give.... 
So whether it is a private or a public facility, people should have basic knowledge of anatomy. Only then will they understand if I talk about the procedure. If they understand they will ask questions and I can talk to them. So education [of the client] is important if information is to be given. (Dr. SL, 40 years, 14 years experience, public facility)

Providers in both public and private facilities noted that clients in private settings tended to be better off and better educated, and therefore were more likely to demand information than other women.

In private practice we can use costly methods [because clients are well off]... patients ask more questions [as they are educated]. Their motivation is high. (Dr. WT, 54 years, 28 years experience, public facility)

Providers also expressed fears that the provision of comprehensive information about sterilisation would dissuade poor or poorly educated clients from accepting the procedure:

If we keep informing uneducated people, they won't turn up [for sterilisation]. If we tell them the details of the procedure they won't come. (Dr. UP, 37 years, 15 years experience, public facility)

I: Do you give different information to educated and uneducated clients?

R: I tell educated people all the side effects as well as the advantages [of sterilisation]... but I tell the uneducated only the advantages. I tell them very little about the side effects, otherwise they won't accept the procedure. (Dr. SR, post-graduate student, 24 years, 4 years experience, public facility)

\section{Providers' attitudes to client involvement}

In many cases, providers reported that sterilisation was the method preferred by both the provider and the client and as a result, interaction tended to be minimal. The doctor who performed the sterilisation almost always took the decision about the procedure to be followed and the timing of the sterilisation. Providers had preferences about choosing a particular procedure and when to conduct the procedure, for example, laparoscopy, conventional sterilisation, concurrent sterilisation or interval sterilisation; however, they rarely involved clients in these discussions on the choice or timing of the procedure. Only when clients raised concerns or questions did providers engage in dialogue, which was generally to convince the woman to adopt the procedure or to dismiss her misconceptions about sterilisation rather than to discuss alternative methods of contraception:

I: How much time do you spend with each patient?

$\mathrm{R}$ : We spend very little time, but with some clients we do spend time... if they have misconceptions about sterilisation or if they are not able to take a decision, we help them take a decision. (Dr. SL, 40 years, 14 years experience, public facility) 
$\mathrm{R}$ : Some women think that after sterilisation they will have less energy, or will not be able to do hard work, or that they will put on weight.

I: How do you deal with these concerns?

R: I don't talk much. I insist that they come for a check-up if they have any problems. (Dr. SM, 33 years, 17 years experience, public facility)

Providers' attitudes were particularly judgemental of women who reported sterilisation failure or alleged negligence on the part of the provider. Providers indicated that such allegations were baseless and that women who complained were poorly informed, "unaware and ignorant" about the medical reasons for failure or were "knowledgeable but money-minded".

\section{I: What about failures in sterilisation?}

$\mathrm{R}$ : There is a 0.5 percent chance of intra-uterine tubal pregnancy. It is because of the tissues joining. Failure cases are taken to court. We are not here to perform "miracles". These uneducated people don't understand. They are stupid. (Dr MT, 36 years, 7 years experience, public facility)

In this context of poor provider-client interaction and the reluctance of providers to discuss clients' concerns, clients tended to distance themselves from doctors and to seek information from nurses, para-professionals and other hospital staff who were perceived to be more approachable. Nurses reported that clients approached them to clear their misconceptions, as indicated in the following interaction:

R: Some will say that they will put on weight, have stomach pain and back pain after sterilisation.

I: What do you tell them?

$\mathrm{R}$ : I tell them that there is no connection between the two; that they should not worry, that nothing will happen. Some feel confident but some continue to have doubts.

I: Do they ask you anything else?

$\mathrm{R}$ : Yes, some ask me whether the doctor will change the position of the uterus and turn it upside down. I tell them that it is not like that; that the doctor will cut the tube and tie a knot, that is all. (Nurse RD, 34 years, 7 years experience, public facility)

Providers rarely made an effort to counsel clients' husbands on the choice of family planning method or the relative advantages of vasectomy over tubectomy. Some providers noted that both men and women were not in favour of vasectomy as they had misconceptions about the adverse effect it would have on their sexual life and their ability to work, attitudes providers believed were too deeply ingrained to change. Others argued that since husbands did not generally accompany their wives to the facility, it was difficult to counsel them; even husbands who did accompany their wives did not come as clients, and therefore the husband was not their responsibility. Providers also reported that husbands could take offence to being advised on considering vasectomy as a family planning method.

I don't tell the husband personally because usually men are not the patients. It is the women who are the patients. When husbands accompany their wives, I cannot advise the busbands directly. Many husbands would not like it; they may say that they have not come here for advice. (Dr. NP, 43 years, 18 years experience, private facility) 
Gender biases were also evident among providers when they advised clients to undergo tubectomy and not vasectomy, for example:

I: So will you motivate clients for vasectomy?

$\mathrm{R}$ : Even our Chief is against vasectomy; if anything happens to the woman and she dies, he can't marry another woman because he has undergone sterilisation. So she [Chief] won't advise the busband to undergo vasectomy. (Dr. SR, post-graduate student, 24 years, 4 years experience, public facility)

R: Normally we prefer the women to get operated.

I: Any reasons?

$\mathrm{R}$ : With vasectomy also there are chances of failure...If it fails and the woman becomes pegnant... then there will be a lot of tension in the family. We should take this into account. If the woman undergoes sterilisation, then we know for sure that there is no chance... she is secure. (Dr. RJ, 36 years, 13 years experience, private facility)

A few did however, admit that they needed to meet and counsel husbands as well:

I: Do doctors make an effort to meet the husbands?

R: May be....May be we are not doing enough....We need to meet the husbands and motivate them. (Dr. KA, 43 years, 15 years experience, private facility)

\section{Compulsion in client-provider interaction}

Findings show that in their interactions with clients, providers tended to use coercion, both overt and covert, to compel women to undergo sterilisation. Providers used terms such as "strongly motivate," "make them accept," "stress [the method]," "threaten, get angry with them [the client if she resists]" while describing how they make women accept family planning. Providers from the public sector were more likely to include elements of compulsion in their interactions with clients. For example:

I: How do you motivate women for sterilisation?

R: Mostly we compel - not like that — we educate them and motivate them ... literally speaking, we compel them to accept. We strongly motivate them.

I: What do you mean by strongly motivate?

R: Meaning almost like compulsion. (Dr. UP, 37 years, 15 years experience, public facility)

Almost half of all providers interviewed agreed that they compelled women to undergo sterilisation after two children. Women who came for antenatal checkups or those who came to deliver their child in the hospital were also subjected to coercion. Some providers reported that they insisted that newly-delivered women accept sterilisation, threatening to deny them discharge certificates or to provide care to the newborn if they did not do so. Indeed, providers justified these stringent measures by arguing that they themselves faced pressure to recruit sterilisation acceptors, especially among women with two or more children: 
If they have two children we must compel them to get sterilised. (Para-professional D, 44 years, 17 years experience, public facility)

After the third or the fourth child, the woman must undergo sterilisation, if not the Chief will check... she will scold us.... Because of this pressure, we can achieve 100 percent of our target... by using compulsion. If the patient is not willing, then we will not give her the case sheet or discharge summary. We will not allow her to return for post-natal check-ups afterwards. Many patients agree because if they don't get the notebook, it is a problem to get a birth certificate for the newborn baby. (Para-professional H, 41 years, 21 years experience, public facility)

I: Do you face pressure to achieve targets in family planning?

$\mathrm{R}$ : There is pressure to do a certain number of operations. We are not able to [achieve targets]....We try and threaten patients by saying that we won't give them their discharge certificates, birth certificates, etc. and instead will give them only a certificate of Discharge Against Medical Advice. They run away. In review meetings we are pulled up [for not achieving targets]. The Government doesn't understand. (Dr. MT, 36 years, 7 years experience, public facility)

Although most providers were aware that officially, targets have been withdrawn, they reported that targets continued to be set, and referred to them as "indirect targets," or "expected coverage orperformance". Effectively, providers at all levels—-from lower level staff to assistant doctors and department heads-were expected to recruit acceptors for different methods depending on parity. ANMs in the public sector were primarily responsible for motivating women with two children to accept sterilisation. Poor performance in meeting family planning targets was clearly not tolerated:

But we have indirect targets. 100 percent of women who come for the third, fourth or fifth delivery must be sterilised. If it is a second delivery, 50 percent must be sterilised and 50 percent provided with a $\mathrm{Cu}-\mathrm{T}$ [IUD]; and for those who come for the first delivery, 50 percent must be covered with a Cu-T. Otherwise, during the review meeting, the Chief will ask for reasons for not meeting these targets. (Para-professional D, 44 years, 17 years experience, public facility)

Providers also reported that they coerced women seeking abortion services to adopt sterilisation. In many such cases, conditions were imposed on abortion-seekers who had two or more living children, and abortion services were offered only if sterilisation was also accepted.

We even threaten them [before discharge] that if you come for abortion again, we won't do it [so it is better to do the sterilisation now]. (Dr. UP, 37 years, 15 years experience, public facility)

I: Are there any conditions stipulated before doing an MTP [medical termination of pregnancy]?

$\mathrm{R}$ : If married women with two children come for an MTP, we will do the MTP with sterilisation, otherwise we won't admit the patient. (Para-professional D, 44 years, 17 years experience, public facility) 
Some women admit themselves here for an abortion to be followed by sterilisation, but after the abortion is performed, they run away from the hospital without undergoing the sterilisation. (Nurse RD, 34 years, 7 years experience, public facility)

Several study participants stated that there was an "order" stating that no woman should be discharged from the hospital without accepting a contraceptive method; some also noted that every staff member should work towards winning the "award" (a shield) given to the hospital reporting the best performance in family planning:

The Chief has issued an order that we should not discharge the patient from the hospital without her adopting a family planning method. (Para-professional RV, 33 years, 12 years experience, public facility)

\section{I: Are you under pressure to promote any method?}

$\mathrm{R}$ : Yes, there is pressure. If the numbers are less for any method, we have to answer to the superior because we have to win the award. (Nurse RT, 51 years, 29 years experience, public facility)

On the whole, providers from private sector facilities — who did not face the same pressure as their counterparts in public facilities - appeared less likely to pressurise clients to accept sterilisation. They were also more likely to offer newly delivered women the choice of returning for sterilisation at a later date and recognised reasons such as difficult labour and delivery, economic constraints, important family functions and children's examinations that may prompt women not to undergo sterilisation along with the delivery or abortion. However, some providers in private facilities admitted that they pressurised women to adopt family planning. For instance, one provider reported that she would not admit a woman for a second delivery unless she agreed to undergo sterilisation:

$\mathrm{R}$ : If it is a case of second caesarean section [CS], then we tell the woman that she should undergo sterilisation along with CS. We tell her as if it is a rule that women have to follow. If we explain scientifically they accept. We cannot talk to them in emotional terms. (Dr. NP, 43 years, 18 years experience, private facility)

In general, providers disapproved of the pressure placed on them to force women to undergo sterilisation. Nevertheless, most of them favoured imposition of the two-child norm and the use of incentives and disincentives to achieve this norm. ${ }^{3}$ Providers from both private and public facilities expressed concern about the high rate of population growth: some defended the use of "force", others supported the idea of promoting the one-child norm, and one provider even alluded to the Emergency period (1975-77) ${ }^{4}$ and its apparent role in stabilising population growth in the country.

\footnotetext{
3 After the recent tsunami in 2004 that affected parts of Tamil Nadu, some providers reported that they would not advise their clients to undergo sterilisation soon after the second delivery.

${ }^{4}$ In 1975, a state of Emergency was declared in India. During this period, the target-oriented approach became extremely coercive.
} 
These interactions suggest that the quality of decision-making suffers because of the attitudes and biases of providers. Our interaction with providers suggests that by and large, information on the possible side effects of a method was unlikely to be provided unless women explicitly demanded it. Also, many doctors appeared to have a low opinion of women's ability to comprehend medical matters. There was also a bias against women from poor socio-economic backgrounds. Providers were also dismissive of the concerns expressed by women and labelled them as misconceptions, and in the process appeared to be indifferent or threatening to clients. In such situations women sought information and cleared their doubts from nurses, ANMs, counsellors or social workers. Many doctors did not see any need for couple counselling or even discussion of male methods of contraception. It appears that the unfriendly nature of provider-client interaction neither inspires confidence in the client about clearing her doubts and misconceptions, nor allows her to obtain sufficient clarity to enable her to make a free and informed decision.

Further, providers use women's silence to justify that women do not expect more information or have much concern about the likely side effects of sterilisation, which leads to poorly informed decision-making. When clients express an interest in sterilisation, providers rarely involve them actively in the reassessment of their reproductive goals and the decision to undergo the procedure. In fact, providers play a dominant role in the decision on the method of contraception that the client needs to adopt, and even to the extent of pressurising women by denying services to which they are entitled to if they do not accept sterilisation. Consent in many cases is extracted from clients through compulsion or coercion.

\section{Quality of written consent taking: How informed and free?}

In contrast to the IPPF and MOHFW guidelines on ensuring informed consent in family planning services, which emphasise the need to explain, as well as inform the client, the need to use the local language that the client can understand and to view informed consent as part of a larger counselling activity, most providers perceived the provision of information as a mere necessity to be completed. Only a few providers from the private sector were able to distinguish between information giving, consent taking and decision-making; and these providers gave information to clients much before taking their signature.

\section{Purpose of the consent form}

In public sector facilities, two types of written consent are required at the time of sterilisation: one on the case-sheet and the other on a prescribed consent form printed in Tamil. The signature on the case-sheet is usually taken from the client herself, or from her spouse or a close relative. The signature on the case-sheet attests that the client is willing to undergo sterilisation along with anaesthesia. It has additional clauses for specific situations such as "In spite of suffering from heart disease, I am willing"; "In spite of having two female children, I agree"; "I agree to undergo abortion with anaesthesia followed by family planning," and so on. On the government-supplied consent form, the woman is the signatory; her signature is taken just prior to surgery, either while she is waiting to enter the operation theatre or a few hours before surgery. In private facilities, written consent is procured on a printed form;

$18 \mid$ Rajalakshmi 
its content varies between hospitals. While most private hospitals had a generic consent form for all surgeries, a few had a specific form for sterilisation. Most of these forms were in English.

Service providers themselves appeared to be somewhat uncertain about the purpose of the consent form. They perceived the signature on the case-sheet as consent and the signature on the consent form as an administrative requirement for the purposes of disbursing compensation money ${ }^{5}$ rather than as an affirmation of the client's willingness to undergo the procedure.

I: Do you have separate forms for sterilisation?

$\mathrm{R}$ : We write on the case-sheet, "I agree to undergo sterilisation under anaesthesia".

I: What about the other form that is longer and is printed on both sides [i.e, the governmentsupplied consent form??

$\mathrm{R}$ : That we use for the distribution of compensation money to patients. The patient only has to sign it. (Nurse RT, 51 years, 29 years experience, public facility)

\section{Administration of the consent form}

The curriculum of providers' courses on consent was limited to the need for a signature on the consent form before carrying out any procedure. None of the providers interviewed had undergone any training in family planning counselling or ethics. Three providers had attended conferences and lectures on these issues, and post-graduate students reported that they learnt about information giving/counselling while observing the doctors.

In a number of cases, doctors reported that the task of obtaining signatures and administering the consent form was left to the nursing or para-professional staff. Indeed, doctors by and large neither monitored nor supervised the process of consent taking. The majority of doctors could not confirm that the consent forms were being read out and adequately explained to women by those assigned to this task. In fact administering the consent form was perceived as "everyone's" or "anyone's responsibility".

The Sister on duty is in charge of the consent form. There is no particular Sister responsible, whoever is available will take consent from the client. (Nurse SY, 36 years, 7 years experience, private facility)

A few doctors in private facilities reported that since they had given the client all the required information with regard to the surgery in the course of previous consultations, there was no need to explain the consent form while obtaining the client's signature. Only one provider reported that before starting surgery, she checks with the patient about whether she has read and signed the consent form. Several providers were of the opinion that it was the woman's responsibility to ensure that she understood the content of the consent form. Many believed that patients were not interested in understanding its content, as suggested by providers from both public and private facilities. For example:

\footnotetext{
${ }^{5}$ In public hospitals, Rs. 200 is paid to every woman who accepts sterilisation.
} 
I: Do women read the consent form?

R: You should ask that question to the patients. How would I know?

I: In your experience what do you think?

R: All of them should read it... if they are literate. (Dr. P, age not disclosed, 30 years experience, public facility)

I: Do women read the form or is it read out to them?

$\mathrm{R}$ : They have to read it or ask someone to read it to them. If they are not interested what can we do? (Dr. KM, post-graduate student, 33 years, 15 years experience, public facility)

It was observed that in both public and private sector facilities, nurses and para-professionals were responsible for administration of the consent form. Nurses and other staff entrusted with the written consent procedure reported that their main task was to take the woman's signature after orally confirming her willingness to undergo the procedure. Only a fewparticularly those from private facilities - reported that they handed the forms to women and expected clients to read them. The majority admitted that they neither read out nor explained the form to the client, and assumed that the doctor would explain the content of the form to them. For example:

I: When you take the signature, do you read out the form to the client?

$\mathrm{R}$ : The doctor would have already spoken to the patient, and would have already explained everything before coming bere. (Nurse SN, 30 years, 10 years experience, private facility)

They [Health Visitors] don't read out the form. But everything is mentioned in the form. Patients are supposed to give their consent after they read the form or it is read out to them. (Nurse RD, 34 years, 7 years experience, public facility)

I: How much time do you spend for taking their signature?

$\mathrm{R}$ : Immediately after we give the form, we take it back. But I have not read the form. (Nurse RT, 51 years, 29 years experience, public facility)

Providers in the public sector, and some in the private sector, cited lack of time, work pressure and lack of interest as reasons for not explaining the consent form. One provider reported that she took signatures from women after they were cleared for anaesthesia and just before they entered the operation theatre so as to save forms that were apparently in short supply.

Clearly, providers — both doctors and the other staff — perceived that obtaining a signature on the consent form was more critical than explaining its content to the client. The administration of the consent form was perceived as time consuming, unimportant and was often relegated to lower level staff. Consent taking was not viewed seriously by the hospital administration as providers were unsure as to who was finally accountable. There was also a perception that the onus was on the clients to read, comprehend and clear their doubts on the content of the form, thereby absolving the providers of any responsibility. 


\section{Need for consent from husband or other family members}

Although most providers agreed that in principle the consent form required the signature of only the woman undergoing the procedure, in practice, many encouraged the husband or relative to counter-sign the consent form. This was largely perceived as a form of protection for the provider.

It is preferable to have the husband also sign the consent form; it solves a lot of problems later unless the patient herself guarantees that it doesn't matter or that her husband is out of station and has told her to go abead with sterilisation. In that case we ask the next closest relative- the mother or the in-laws — to sign as a second witness... as later there may be a family rift or a fight in the family because of the sterilisation. (Dr. RG, 48 years, 24 years experience, private facility)

While both public and private sector providers reported a preference for the form being counter-signed, public sector providers appeared more ready to undertake the procedure without the husband's signature; in contrast, private sector providers were hesitant about performing sterilisation in the absence of a clear consensus between the partners, even if it meant loss of time, for example:

If there is any hesitation we don't perform the sterilisation.... Because if the patient has any doubt, I ask the couple to come and talk. to me; if either of them has any hesitation, there is no way that we go ahead. (Dr. SJ, 42 years, 21 years experience, private facility)

Written consent was almost always sought from a family member in situations involving risk, such as if the woman had a medical condition that could place her at risk at the time of sterilisation or if the newborn was premature. In certain other situations too, written consent was always sought, such as if the sterilisation was to be performed on a woman with one child or two daughters, or if the sterilisation was decided based on the sex of the second-born in a caesarean delivery.

Providers reported that the major concerns that prompted them to take a second signature were to protect themselves from problems created by family members that may arise due to medical complications in the course of the surgery, to protect themselves from abuse or threats from the husband or family members who may question their authority to perform the sterilisation, to "help" the woman to "preserve" her marriage and to ensure "peace" in her marital family.

\section{I: Is the husband's signature important?}

$\mathrm{R}$ : Now they say it is not needed. According to me it is a must.

I: Why do you feel so?

$\mathrm{R}$ : If he comes to know later [about the sterilisation], he may divorce her and marry another woman. (Dr. SR, 52 years, 32 years experience, private facility) 
Even providers who do not insist on the husband's signature reported that they confirm from the client orally that the husband has indeed consented to the procedure.

In short, providers regarded the consent taking process as a procedural requirement, and in most cases, had not followed the suggested guidelines for taking informed consent. The process was clearly neither informed nor free; in most cases providers did not feel it necessary to explain the consent form to the client, or felt that it was the client's responsibility to ensure that she understood the content of the form. Indeed, almost half the providers reported the practice of getting husbands to countersign the consent form. 


\section{Providers' perceptions of the importance of informed consent}

The study also enquired about providers' perceptions of informed consent. Findings suggest that providers had varying perceptions of the importance of the informed consent procedure. However, most providers viewed the process more as a formality than as the right of a client or even as an important procedure for improving client satisfaction.

\section{Informed consent as an information providing process}

Several providers, particularly doctors and nurses, seemed to understand the basic concept of informed consent. As the following quotes indicate, they perceived informed consent as a process whereby women were informed about the method of sterilisation before consenting to undergo the procedure.

Providing information and getting the client's consent is called informed consent. (Para-professional $\mathrm{H}, 36$ years, 16 years experience, private facility)

It [informed consent] means we should explain the procedure to the patient, such as what we are going to do, how we will do it. We have to talk about the merits and demerits of the procedure and likely complications. We should explain everything, then we should ask for their consent. (Dr. SM, 33 years, 17 years experience, public facility)

Asking for signature is different, what we convey to the client is different. How the client has understood the information is important. We can give them all the information but we should make them understand it. The language is very important. (Dr. MI, 44 years, 15 years experience, private facility)

\section{Informed consent as a means of preparing for surgery}

Many providers, especially para-professionals, perceived consent as linked to the process of preparing the woman for surgery; that is, as part of the process of screening the client, instructing her about diet and other aspects of pre- and post-operative care and allaying her fears about surgery.

$\mathrm{R}$ : What do you mean by informed consent?

I: We prepare the patients mentally for the operation. If the patient is afraid of surgery, I ask her to be brave. We explain the procedure and tell her what the doctor is going to do. (Nurse $\mathrm{RD}, 34$ years, 7 years experience, public facility)

Informed consent is informing her of all the procedures that she will undergo in preparation for the operation, such as ECG, etc. (Dr. TA, 43 years, 12 years experience, private facility) 


\section{Informed consent as a signature on a form}

Several providers in both the private and public sector could not differentiate between the concept of informed consent and the requirement of a signature on the consent form. Indeed, these providers perceived that the most significant aspect of the informed consent procedure was procuring a signature on the form.

\section{I: Have you heard of informed consent, doctor?}

$\mathrm{R}$ : Informed consent is what we are doing, no? Informed consent is what we are taking [i.e., signature on the form]. (Dr. KA, 43 years, 15 years experience, private facility)

\section{Informed consent as a medico-legal requirement}

Several providers highlighted the importance of informed consent as a legal requirement:

When we inform the client, legally we are clear. Informed consent is a legal document and is a must. All doctors should provide some sort of information to the patient. (Dr. BK, 35 years, 5 years experience, private facility)

I think it [informed consent] is a must because it is required by law. We cannot go against the law...my preference is that we should definitely provide information to the patient. (Dr. RG, 48 years, 24 years experience, private facility)

Providers, including doctors, nurses and post-graduate students, underscored the extent to which consent taking protects the doctor or the hospital from legal problems, including allegations of negligence or even problems arising from differences between the woman and her family. Therefore, taking not only the signature of the client, but also that of the client's husband or other family members was seen as beneficial in enabling doctors and facilities to protect themselves should a medico-legal case arise:

I: What is the use of informed consent?

$\mathrm{R}$ : It is only for our use. Later on if there is failure or death, we can say, "We informed you". (Dr. PL, 50 years, 20 years experience, public facility)

If they [clients] do not sign the form, then there can be a problem. If they sign, we are not responsible if anything happens to them. The patient knows that we are not responsible if they have any problems, so the patient puts the signature. (Nurse MM, 22 years, 4 years experience, private facility)

Doctors benefit the most by taking consent from patients. If anything happens, the doctor is on the safe side. This is the reason why doctors are giving a lot of importance to consent. Without consent, they won't perform the operation. (Dr. GN, post-graduate student, 24 years, 1 year experience, public facility)

As already noted, several providers were of the view that in cases of sterilisation failure, patients can bring legal charges against them "unduly" for negligence. While reasons for 
failure could be many, providers felt they were not accountable for any kind of failure. Providers argued that litigating patients were influenced by lawyers and sought to extort compensation from the provider; indeed, they would rather bring charges against the provider than return to the facility in case of failure or complications.

While most providers were of the view that the consent signature can protect them from allegations of medical negligence and failure, only one doctor was aware that it was not merely the consent signature but a proper documentation of the decision-making process that would protect the physician:

Whether you have taken written consent or not, that piece of paper has no legal value. Even if you go abead and do family planning without consent [signature], if she goes to court and the court asks you if you have taken consent [signature], if everything is documented, you can win the case.... You can lose the case if you have not provided reasonable information which she is supposed to know. We document everything. (Dr. BK, 35 years, 5 years experience, private facility recounting a lecture by a medico-legal expert)

\section{Informed consent as a two-way communication process and a client's right}

In contrast to those perceiving informed consent as a formality, a few providers, mainly from the private sector, viewed informed consent to be a process involving a two-way communication between the provider and the client, in which the client feels free to seek clarifications from the provider, and where the client is given sufficient time to review her options. These providers perceived the need for open and honest communication with their clients, and noted that the process of informed consent built a relationship of trust and confidence in the provider.

It [informed consent] builds rapport between the doctor and patient, obviously we tell them everything. The patient knows that the doctor is being free and frank with her and is not hiding any facts. (Dr. RG, 48 years, 24 years experience, private facility)

One thing good about informed consent is that you have to tell the client whatever she wants to know or needs to understand. I am not bothered about whether the patient wants or doesn't want to accept [the method]. It is important that I should inform her about what is necessary for her, and then she will come back. [to get clarifications on the procedure]. The second part of it is that when patients ask questions, we have to listen and try to answer their questions. (Dr. BK, 35 years, 5 years experience, private facility)

One provider - a post-graduate student—-perceived the informed consent procedure as intended to protect the client's rights.

Everything should be told to the patient. Consent is important; after all we are human beings, so we should respect other human beings. Nobody likes other people touching their bodies. So I inform the woman that I am going to feel her stomach for examination. Even if she does not ask 
any questions, I will seek her consent by asking her specific questions. So consent is important before we do anything. (Dr. SU, post-graduate student, 29 years, no experience)

Providers acknowledged that the consent procedure benefits both the provider and the client. A few they reported that it creates awareness about the procedure among clients, and builds a mutual sense of satisfaction or rapport between the client and the provider. For example:

I: What is the use of informed consent?

R: It is good for the patient and also for the safety of the doctor.

I: In what sense is it good for the patient?

$\mathrm{R}$ : They are also made aware that a small amount of risk is associated with any kind of procedure...so that they are also mentally prepared.

I: And for the doctor?

R: We need to protect ourselves. (Dr. LR, 36 years, 13 years experience, private facility)

I: Who will benefit?

$\mathrm{R}$ : Both the patient and the doctor or the hospital. The patient will have the satisfaction that the doctor has given her the information, the doctor also has the satisfaction that the patient was told everything regarding the procedure. (Dr. MI, 44 years, 15 years experience, private facility)

In short, providers perceive informed consent in many ways. Many emphasise its importance as a legal tool that protects the provider; several consider it a formality or simply a signature on a form. Few, in contrast, perceive the consent procedure as a means of building trust or enabling the woman to exercise her right to determine the kind of procedure she will undergo. 


\section{Conclusion and recommendations}

This study highlights providers' experiences and perceptions of the process of informed consent in female sterilisation services in facilities in Chennai. While national and international guidelines for ensuring informed consent in family planning services have detailed the procedures to be followed, the study findings underscore that in most cases providers did not follow the guidelines. Although access to information is a client's right, the findings show that providers give clients incomplete information on sterilisation as they harbour misconceptions that giving clients information on alternative methods of family planning or the associated risks and failures would bring down acceptance of sterilisation. Moreover, providers' judgemental attitudes, including the perception that women, especially from poor socio-economic backgrounds, cannot comprehend information or do not expect to be given details, distance them from women and create an unsupportive environment for an open discussion of women's concerns. Indeed, women who are less powerful and lack negotiating skills are expected by providers not to demand their rights within the hierarchical medical institutions, particularly in the public sector. The quality of client-provider interaction suggests that providers still act on the principle that the "doctor knows best," rarely involving clients actively in decisions, and more disturbingly, compelling or coercing them to adopt sterilisation. Providers themselves reported they were under pressure to recruit acceptors, and seemed to have internalised the need to advocate sterilisation, whether they were in public or private institutions. Finally, consent taking is not taken seriously by all levels of providers and is seen more as a necessary formality rather than as a mechanism to inform women and ensure free decision-making. More importance is given to taking a client's signature on the consent form as it is perceived to protect the provider/facility in medico-legal matters. There is no recognition of informed consent as an ethical duty or as a client's right.

This study has important programmatic and policy implications. Findings strongly suggest the need to train and sensitise providers in public as well as private facilities on their ethical responsibilities of ensuring free and informed contraceptive decision-making. Awareness needs to be built of informed consent as a significant component of quality of care, a client's right and the ethical duty of those in health delivery systems. Efforts need to be made to incorporate a comprehensive discussion on informed consent in the main curriculum of medical education, nursing and para-professional courses. The principles of informed consent should be effectively translated into practice, which would facilitate learning by observation for students. Training of providers on communication and counselling skills, gender and reproductive health would facilitate the implementation of informed consent processes. Hospital administration systems need to show a stronger commitment to informed consent by setting up systems to allocate responsibilities, monitor work related to informed consent processes, redress clients' grievances and hold defaulters accountable. Institutional, state and national policies - whether written or unwrittenthat affect the quality of informed consent should be modified and reflected in the relevant laws to ultimately protect the rights of clients considering contraception. 


\section{References}

Baill, I. C., V. E. Cullins and S. Pati. 2003. "Counselling issues in tubal sterilisation," American Family Physician 67(6): pp. 1287-1294.

Bruce, J. 1990. "Fundamental elements of the quality of care: A simple framework," Studies in Family Planning 21(2):61-91.

Cook, R.J., B.M. Dickens and M.F. Fathalla. 2003. Reproductive Health and Human Rights. Oxford: Clarendon Press.

Gupte, M., S. Bandewar and H. Pisal. 1999. “Women's perspectives on the quality of general and reproductive health care: Evidence from rural Maharashtra," in Improving Quality of Care in India's Family Welfare Programme, ed. M.A. Koenig and M.E. Khan. New York: Population Council, pp. 117-139.

International Institute of Population Sciences (IIPS) and ORC Macro. 2000. National Family Health Survey (NFHS-2), 1998-99: India. Mumbai: IIPS.

International Institute for Population Sciences (IIPS) and Johns Hopkins University. 2005. Follow-up Study of NFHS-2 Respondents in Four Indian States: Final Report. Mumbai: IIPS.

International Planned Parenthood Federation (IPPF) website. "IPPF medical and service delivery guidelines for sexual and reproductive health services, Chapter 8: Female and male sterilisation," available at <http:/ / content.ippf.org/output/ORG/files/ 5913.pdf $>$ accessed on 22 August 2006.

Kennedy, I. 1991. Treat Me Right: Essays in Medical Law and Ethics. Oxford: Clarendon Press.

Khan, M.E., R.B. Gupta and B.C. Patel. 1999. "The quality and coverage of family planning services in Uttar Pradesh: Client perspectives," in Improving Quality of Care in India's Family Welfare Programme, ed. M.A. Koenig and M.E. Khan. New York: Population Council, pp. 44-69.

Kim, Y.M., A. Kols and S. Mucheke. 1998. "Informed choice and decision making in family planning counselling in Kenya," International Family Planning Perspectives 30(1): $4-11 \& 42$.

$28 \mid$ Rajalakshmi 
Kumar, R. 2001. Human Rights Dialogue (1994-2005), Series 2, Number 6. "Rights and the struggle for health: Online exclusive," available at <http:/ /www.cceia.org/ resources/publications/dialogue/2_06/online_exclusive/652.html $>$ accessed on 6 September 2006.

Ministry of Health and Family Welfare (MOHFW). 1999. Standards for Female and Male Sterilisation. New Delhi: Government of India.

Ministry of Health and Family Welfare (MOHFW). 2005. Manual for Family Planning Insurance Scheme. New Delhi: Government of India, available at < http:/ / mohfw.nic.in/ dofw\%20website/Planning\%20Insurance\%20Manual.pdf > accessed on 5February 2007.

Muraleedharan, V. R. 1999. "Characteristics and structure of private hospital sector in urban India: A study of Madras city," in Private Health Sector in India: Review and Annotated Bibliography. Mumbai: CEHAT, Chennai: IIT, New Delhi: JNU.

Murthy, N. 1999. "The quality of family welfare services in rural Maharashtra: Insights from a client survey," in Improving Quality of Care in India's Family Welfare Programme, ed. M.A. Koenig and M.E. Khan. New York: Population Council, pp. 33-48.

National Bioethics Advisory Commission. 2001. "Chapter Three: Voluntary Informed Consent," in Ethical and Policy Issues in International Research: Clinical Trials in Developing Countries, Vol. 1: April, pp. 35-53, available at <http://bioethics.georgetown.edu/ $\mathrm{nbac} / \mathrm{pubs} . \mathrm{html}>$ accessed on 21 May 2006.

Ravindran, T.K.S. 1999. "Rural women's experiences with family welfare services in Tamil Nadu," in Improving Quality of Care in India's Family Welfare Programme, ed. M.A. Koenig and M.E. Khan. New York: Population Council, pp. 70-91.

Registrar General, India (RGI). 2005. "Fertility tables," available at < http:/ / censusindia.net/ results/fseries_tables/f_series_tables_2001.htm> accessed on 20 January 2007.

Registrar General, India (RGI). 2006. "Maternal mortality in India: Trends, causes and risk factors, 1997-2003," available at <http://www.censusindia.net/ Maternal_Mortality_in_India_1997-2003.doc > accessed on 20 January 2007.

Rotimi, A.K. and P. Eedarapalli website. "Female sterilisation," available at <http://www.sexualhealthmatters.com/v2iss2/article4.html> accessed on 10 September 2004.

Roy, T.K. and R.K. Verma. 1999. "Women's perceptions of the quality of family welfare services in four Indian states," in Improving Quality of Care in India's Family Welfare Programme', ed. M.A. Koenig and M.E. Khan. New York: Population Council, pp. 19-32. 
Sreevidya, S. and B. W. C. Sathiyasekaran. 2003. "High caesarean rates in Madras (India): A population-based cross sectional study," British Journal of Obstetrics and Gynaecology 110(2): 106-111.

Supreme Court of India website. Supreme Court of India, Ramakant Rai and Health Watch U.P and Bihar versus Union Of India and Others, Writ.Petition (Civil). No. 209/2003, available at < http://www.courtnic.nic.in/> accessed on 4 February 2007.

Supreme Court of India website. Supreme Court of India, Samar Ghosh versus Jaya Ghosh, Appeal (civil) 151 of 2004, available at <http://www.courtnic.nic.in/> accessed on 9 April 2007.

Tamil Nadu Government website. Available at <http://www.tn.gov.in/deptst/ EcoIndAllStates.htm $>$ accessed on 7 February 2006.

Tamil Nadu Government, Directorate of Family Welfare website. "Statistical handbook," available at < http://www.tnhealth.org/dfwstat.htm> accessed on 7 February 2006.

Van Hollen, C. 2003. Birth on the Threshold. New Delhi: Zubaan Books.

Verma, R.K. and T. K. Roy. 1999. "Assessing the quality of family planning service providers in four Indian states," in Improving Quality of Care in India's Family Welfare Programme, ed. M.A. Koenig and M.E. Khan. New York: Population Council, pp. 169-182.

Visaria, L. 2000. "From contraceptive targets to informed choice," in Women's Reproductive Health in India, ed. R. Ramasubban and S. J. Jejeebhoy. New Delhi: Rawat Publications, pp. 331-417.

World Medical Association (WMA). 2000. "Declaration of Helsinki: Recommendations guiding physicians in biomedical research involving human subjects adopted in 1964 and last amended in 2000," available at <http://www.wma.net/e/policy/ b3.htm> accessed on 6 September 2006. 


\section{Acknowledgements}

Several people provided valuable assistance during the course of this study. I am grateful to Bhuvaneswari and Sai Santhya for assistance in data collection and entry. I would like to thank Shireen Jejeebhoy, K.G. Santhya, Shveta Kalyanwala and Komal Saxena at the Population Council for their guidance throughout the study and on previous versions of this report. I am grateful to Amar Jesani and Leela Visaria for reviewing the report; Deepika Ganju for her editorial contribution; Vijaya Nidadavolu for overseeing production of the report; and Asha Matta for designing the report. 
